\title{
The Photograph as a Cultural Arbitrator in the Design of Virtual Learning Environments for Children and Young People
}

\author{
Susan Jones \\ University of Sunderland \\ St. Peter's Campus \\ United Kingdom \\ susan.jones@sunderland.ac.uk
}

\author{
Lynne Hall \\ University of Sunderland \\ St. Peter's Campus \\ United Kingdom \\ lynne.hall@sunderland.ac.uk
}

\author{
Marc Hall \\ University of Sunderland \\ St. Peter's Campus \\ United Kingdom \\ marc.hall@sunderland.ac.uk
}

\begin{abstract}
Digital technology, the Internet and mobile communication have made picture taking and sharing ubiquitous. The photograph with its long track record as a representational artefact now portrays individuals in ever broader contexts. The once distinctive practice of the snapshot aesthetic in capturing the banal and everyday has become culturally pervasive and children are key creators, producers and sharers of digital photographs. Designers of innovative digital media for children and young people face real problems in establishing requirements. Early experiments using children's photographs to inspire design and game evaluation methods led to tangible improvements in the user experience. To date however, the benefits of a robust discourse on the vernacular photograph in this context have come secondary to the pragmatics of design. This paper will explore the role of the photograph as a cultural arbitrator in the design of innovative software for personal and social education. It will examine the construct of the photographic index and its changing value in dialogue associated with digital images; will consider how this inherently ambiguous dimension of human experience can be investigated to better appreciate children's affective and cognitive responses to photographs in design contexts and will discuss the benefits and challenges of harnessing the photograph as a cultural arbitrator.
\end{abstract}

Photograph. Culture. Design. Games. Education. Children. Young people.

\section{INTRODUCTION}

As passive subjects in works of art, including paintings, illustrations and latterly photographs, children have been, and still are, consistently portrayed in ways that reflect the cultural perspectives and socio-economic context of the time (Higgonet, 1998). Today, however, through their increasing empowerment and agency, children and young people play an increasingly active role in their own visualisation through the photograph (Luttrell, 2006).

As a consequence of advances in digital technology and in particular the camera phone, Western culture is now characterised by 'ubiquitous photography' and the snapshot has been what Rubinstein and Sluis (2008) describe as the, "... archetypal readymade image: placeholder for memories, trophy of sightseeing, produced in their millions by ordinary people to document the rituals of everyday life".
Young people in their daily lives now use the mobile phone routinely, both quantitatively and in terms of social meaning (Scifo, 2009). They are increasingly recognised as key creators, producers and sharers of this digital content worldwide and the immediacy of sharing photographs has been compared by Palmer (2002) to the sharing of everyday experience itself. These experiences become micro-spectacles - details of everyday life (Lee, 2009), made immediately accessible online through social networks, blogs and wikis, supporting a growing visualisation of cultural context through the snapshot that is unprecedented.

In innovative digital media product design, children and young people, as 'digital natives,' as they were first coined (Prensky, 2001), have a key role to play as design stakeholders (Druin et al., 1999). This is partly because developers have not used and experienced technology in quite the same way as children and young people today, but also because in user-centred design, the importance of taking into account cultural context is widely recognised 
(Shen et al., 2006). In digital media projects the use of photographic methods that help explore the child's cultural context and perspective have been increasingly used to inspire design (Hall et al., 2007), Figure 1.

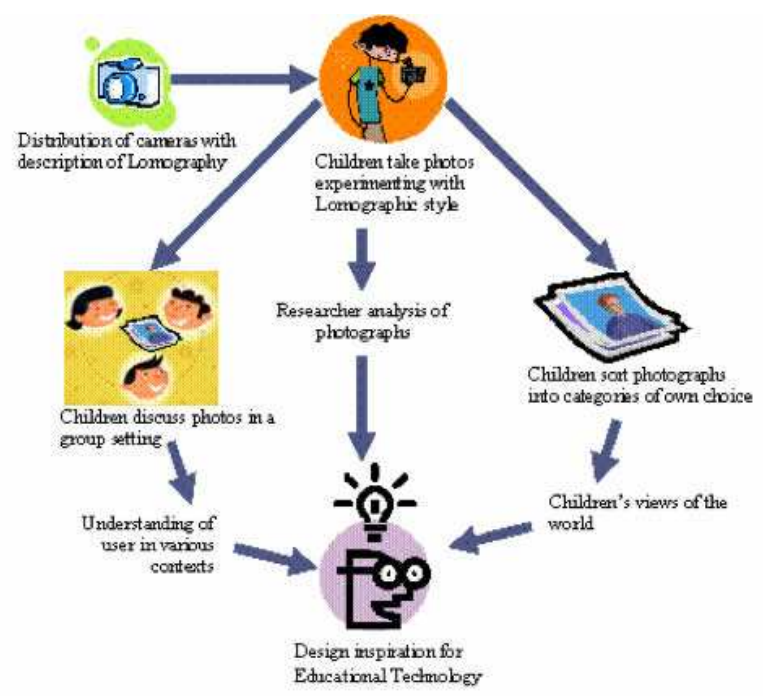

Figure 1: Using photography to inspire design

At this juncture, it is timely to think more critically about the value of the photograph as an artefact that carries cultural meaning; a mediator, an arbitrator of culture itself in this design context. Snapshot photographs have become useful as artefacts for designers because they can capture and portray children and young people in their natural environment (Rasmussen, 2004) and in practical terms this process is valuable because of its authenticity, its veracity, its realness.

A useful place to begin a more theoretical debate around the photograph is to consider one of the most fundamental critical constructs in visual theory, that is, the notion of the index or indexicality of an image. The index was first described by Pierce (1931) who used this construct to account for the physical relationship between the subject as captured on film, and their portrayal on photographic paper. It is this direct physical link between the subject and the image that gives the photograph its remarkable quality. When we look at a photograph of a person, we are strangely influenced by it. It seems to have a power over us that is at odds with its obvious physicality and we attribute to it a personal value which is hard to put into words. It is this physical connection which is central to Roland Barthes's Camera Lucida, as he explains, "...it is as if the photograph always carries the referent within itself" (1993).

Mitchell (2005) describes our response to this indexical quality as our, "...double consciousness" towards images; a relationship that encourages us to vacillate between "...magical beliefs and sceptical doubts, naïve animism and hard headed materialism, mystical and critical attitudes". Photographs are then, on the one had pragmatic tools with which to explore portrayal in cultural context to inform design, but also enigmatic and inscrutable, acting upon our emotions in complex ways that are hard to rationalise and account for.

The objective of this paper is to start a dialogue in the use of the photographic index, or indexicality, to examine the use of the photograph as a cultural arbitrator between users - in this case, children and young people, and the design team in innovative design projects.

The paper will start with an outline of the eCUTE project which aims to design two game based virtual learning environments, one for children and one for young adults; it will explore the construct of the index and its changing value in dialogue associated with digital images and will discuss future plans to investigate the index by examining how children and young users respond to the dimension of the real and fictional in the photograph. The final section of this paper will examine the benefits and challenges of using the photograph as a cultural arbitrator in design and will discuss the implications of this dialogue on critical practice in design contexts.

\section{VIRTUAL REALITY GAME DESIGN FOR CHILDREN'S PERSONAL AND SOCIAL EDUCATION (PSE)}

The design of serious games for children and young people's social and emotional education presents a major challenge, both in terms of theoretical underpinning and technology innovation. These projects can only be achieved in interdisciplinary design teams working with key stakeholders, including users.

\section{1 eCUTE: Education for Cultural Understanding Technology Enhanced}

In the $21^{\text {st }}$ Century the experience of the citizen is to live and work alongside many cultural, ethnic and religious groups, however cultural difference can lead to social stresses and sometimes outright conflict. Helping children and young people to develop empathy for people from other cultures is therefore an extremely important pedagogical goal.

eCUTE (Education in Cultural Understanding Technology Enhanced) is an EU $7^{\text {th }}$ Framework project that brings together experts in pedagogy, cultural theory, psychology, affective computing, user experience design, programming and evaluation from several European and Japanese universities. The project sets out to create two 
immersive role playing games, the first for children aged 9-11 years on cultural conflict called MIXER Moderating Cross-Cultural Empathic Relationships. MIXER sets out to teach children about in-group and out-groups based upon cultural conflict with rule changes. It uses the rule base from the game of Hide and Seek, which differs across different cultures, to provide the culture shock experience, Figure 2a; the second, for young adults aged 1825 years on intercultural communication called TRAVELLER - Train for Virtually Every Locality, Figure 2b.

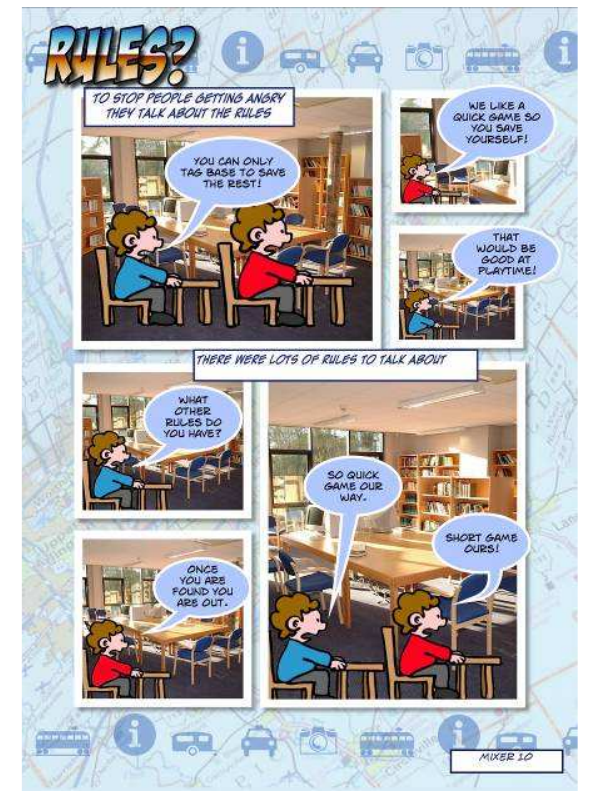

Figure 2a: Low tech paper prototype of MIXER

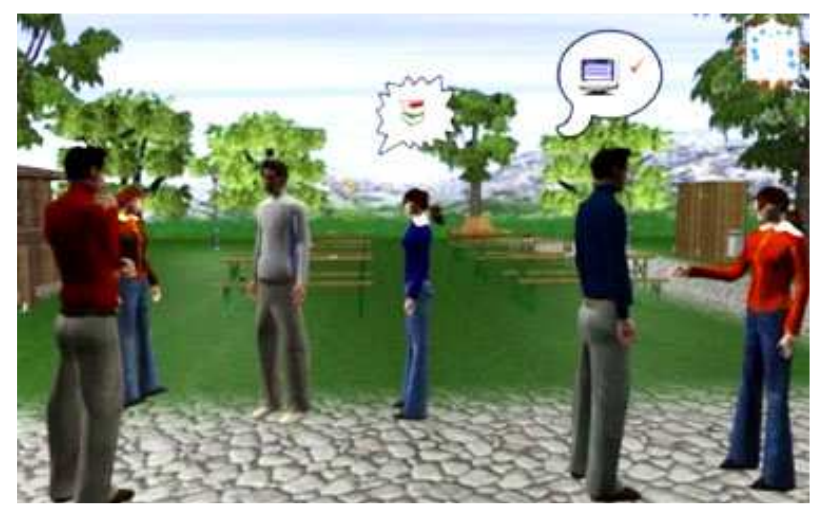

Figure 2b: Mid tech prototype of TRAVELLER

The aim of TRAVELLER is to give young adults opportunities to engage in intercultural communication. Based upon an archaeological expedition scenario, users will be expected to solve a series of mini games or puzzles which help them to gain a better understanding and sensitivity towards diverse cultural behaviours and intercultural dialogue.
At the outset design of both MIXER and TRAVELLER is underpinned by established research in five theoretical domains, namely Bennet's developmental model of intercultural sensitivity (1993), Hofstede's six cultural dimensions (1991), Jan et al. and their parametarisation of culture into autonomous virtual agents (2007), Hill et al. and their culturally affected behaviour model (2006) and Huizinga's Magic Circle of game play (1950), Figure 3.

It is well understood that these kinds of projects require a participative approach involving children and young people as key stakeholders in the design and evaluation process (Iversen \& Brodersen, 2007). Typically using agile methods and user-centred design, the design emerges from multiple cycles of iteration during which the design team work with users to explore requirements (Guha et al. 2004), (Chamberlain, et al. 2006), including testing the validity of design assumptions, eliciting children's own expertise, for example in game structure and sense (Zman, 2008), eliciting contextual knowledge, and assessing design prototypes. Essentially children and young people become part of a larger design consortium through which the design emerges and is validated incrementally.

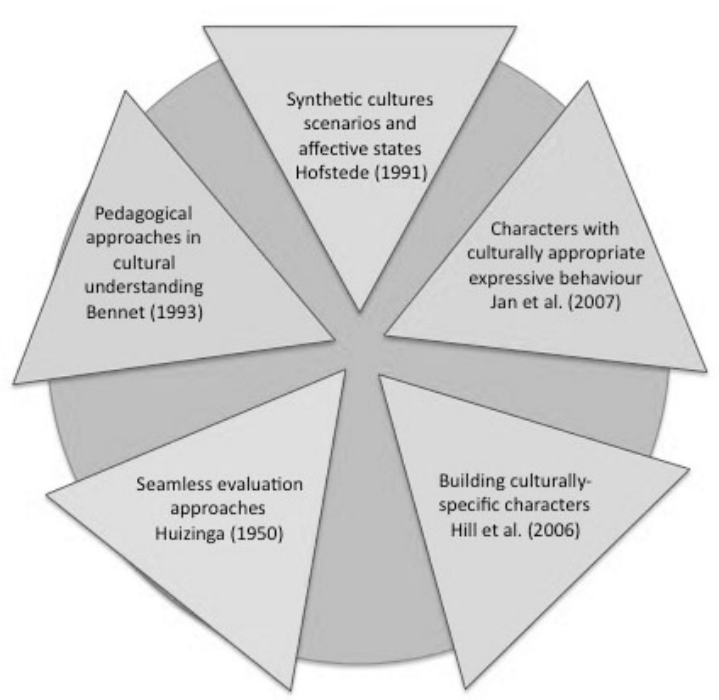

Figure 3: Five theoretical domains underpinning product design in eCUTE

The product is essentially artificial (Simon, 1999), but is generated through successive dialogue and social interaction. However, because of the difficulties of communicating with users, methods are continually being sought which exploit children's own socio-cultural and technological context. Given the ways in which children use photography to mediate their own communication, 
working practices must facilitate a design process that taps into this rich source of cultural information.

\subsection{Participative design practices}

Innovative digital media design practices have for some time recognised the importance of usercentred design and have developed to include participatory methods which allow design features to become established much earlier and to be better understood. Designing for children presents a particular challenge (Christensen \& James, 2000) and research draws attention to the need for approaches that are not only participatory, but that are child-centred, reflecting children's interests and activities (Druin, et al., 1999), Figure 4.

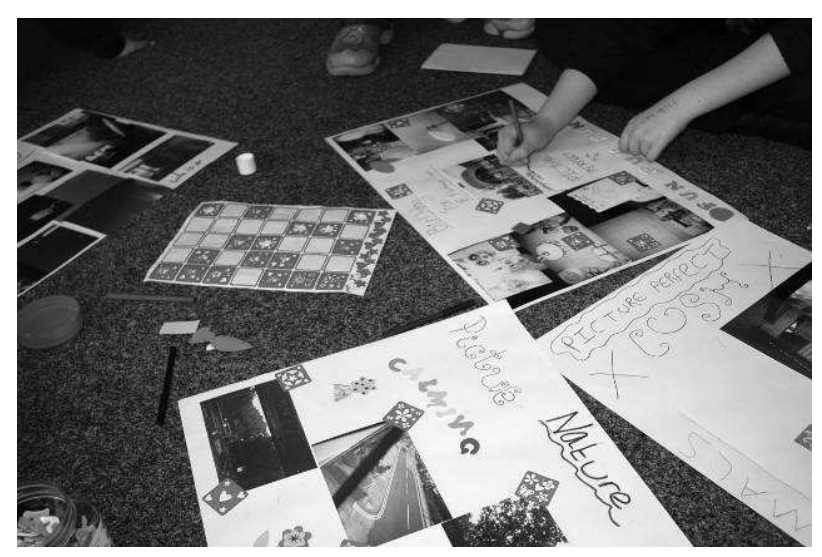

Figure 4: Children engaged in participative design workshops categorising photographs

Bannister and Booth (2005) found that children can be incredibly keen, able and ultimately useful participants. Although the role of children as key design stakeholders is being taken more seriously, many products continue to be designed with very little child input. This is chiefly due to the view that interviewing children is too problematic and that "...children are commonly believed to lack the communication, cognitive and social skills that are the pre-requisites of good respondents" (Christensen \& James, 2000). However, Lewis and Lindsay recognise that "...children's role as consumers and citizens is being taken increasingly seriously in the economy, in law and in social policy" (Lewis \& Lindsay, 1999).

In the eCIRCUS project, Education Through Characters with Emotional Intelligence and Role Playing Capabilities that Understand Social Interaction, the forerunner to eCUTE, photographic methods were used at various stages of the project life cycle. For example, children took photographs to explore their own social world, as artefacts to create a discourse about issues that were important to them, to provide visual material for the development of digital artefacts for sets and as a source of inspiration for the design of other incremental prototypes. The choice of methods adopted was pragmatic, and adapted to suit the user group and timescale. However, the benefits of a robust discourse on the photograph in this context came secondary to the practicalities of design and it is timely to redress this inequity.

\section{PHOTOGRAPHIC THEORY: THE INDEX}

Photography itself as a medium, and the evolving construct of childhood as we understand it, have emerged concurrently, developing alongside one another (Smith, 2003), and indeed are "intertwined" (Tinkler, 2008). Since the seventeenth century, there has been an inseparable link between socioeconomic context, the role of children in society and their portrayal in works of art. A succession of labels including the "innocent child", the "romantic child", and latterly the "knowing child" and the "disappearing" child have been used to describe major cultural shifts in how children have been represented at different periods and in different contexts in recent art and social history (Higgonet, 1998; Postman, 1982).

Recognising this reciprocal relationship is an important first step in this design context, including the transition of the child from the passive subject to the active producer of images. If the photograph can help us to appreciate the child's cultural context, it is important to engage with relevant debates about the integrity of this medium, as this is vital to methodological validity and the most useful place to start.

In photographic theory, the 'index' or indexicality, denotes the physical relationship between the actual subject and their representation in the image and understanding the fundamental impact of the photographic index is central to recognising the value of the photograph as a cultural arbitrator. However, the photograph is a technological innovation that has changed and is changing over time and as Di Bello (2008) proposes, theories like the index, as much as photographs themselves, "...are situated in the specific historic circumstances of their being made, used, reproduced and circulated within a culture". The photograph and its indexical quality, or the visualisation of the real and our response to it, is dynamic, evolving and adapting through new photographic practices.

The onslaught of the digital photograph has therefore challenged the theoretical relevance of the index. As Dzenko explains, "...digital photography "accelerates" or "enlarges" traditional photographic processes because it transforms photographs from objects into data" and this in turn, "...disrupts previous notions of the indexical connection between photographic images and 
"reality"'” (2009). The accessibility of the technology that has evolved to capture the digital photograph has turned its function from one of capturing a memory of a loved one or memorialisation, to one that is more akin to capturing everyday experience, even at its most mundane.

Sutton (2007) describes this connection between the photograph and memory as, "...brittle in explaining the proliferation of "objectless photography, such as that represented by the digital photograph and its emerging culture". However, Batchen (2004) points out, the act of remembering someone is also about the positioning of oneself, about the, "...affirmation of one's own place in space and time, about establishing oneself within a social and historical network of relationships. Photograph albums, "...from tintype and cabinet card albums in the mid and late $1800 \mathrm{~s}$ to digital galleries in the $21^{\text {st }}$ century...serve as mnemonic devices for the moments that bond us together, sparking larger conversations within families" (Mendleson \& Papacharissi, 2010).

So if practices in photography have changed from simply recording memories to registering everyday experience, it is argued here that it is the attenuation of the photographic image itself and our experience of visual multiplicity that has changed and not the indexical quality. Indeed, Dzenko (2007) points out that,“....viewers continue to read digital photographs as representative of reality, a function they maintain despite the transition from analogue to digital".

Bolter and Grusin (1996) describe how older media are used to establish cultural uses of newer media through a process of "remediation", analogous to how the graphic user interface uses office tools in their earlier form, for example folders, desktops and paint boxes. Therefore step changes to the penetration of photographs into the social context reinforce and communicate identity in increasingly more complex ways, and it would be a major oversight to ignore the digital photograph as an important route to the user and their perception of the social world.

Given that in this instance the viewer is actually a target user and design stakeholder, the intrinsic meaning of the photograph and its disparity from one viewer to another needs to be further addressed. Moss (2001) alludes to the, "...deceptive transparency of photographs that leads us to read it at face value" and that, "...this can lead us to focus too narrowly on what the photograph shows, and ask too few questions about what it might mean". The meaning of a photograph is in itself unique to the viewer and there needs to be a much clearer understanding of the way in which people react to, think about and discuss various photographic artefacts.

Contextual factors of viewing have been shown by Mendelson and Papacharissi (2008) to have different cognitive and emotional effects depending upon whether viewers think photographs are real or not; this supports Barthes (1977) notion that visuals are inherently polysemous. "Much of the meaning people receive from photographs, and thus the reactions, depends largely on how they are viewed or defined, rather than any factor inherent within the photographs", (Mendelson \& Papacharissi, 2008); they conclude that in the use of photographs as mediators, careful attention needs to be paid to content, individual viewer differences and viewing context.

Looking at the implications of the index or indexicality as a dimension of experience on participative design practice, it is a particularly difficult concept to investigate. This is partly because of its inherent ambiguity, but also because of its emergence and elucidation in a critical context not normally associated with experimental methods. Yet, it is argued here that a better understanding of the index and indexicality is required as this is the source of a observable affective and cognitive response. Further, it would add to our understanding of how the photograph and photographic practices can add value where communication and dialogue are mediated through the image. A better understanding of how children derive meaning from photographs has major implications in participative design.

\section{INVESTIGATING CHILDREN'S AFFECTIVE AND COGNITIVE RESPONSES TO PHOTOGRAPHS}

As the agency of children and young people is changing, so are their photographic practices but there is still much to learn about their use of the image and visual communication patterns that are emerging, particularly using the mobile phone and similar platforms. Indeed very little is understood about how children react to photographs, both of themselves and their peers in socio-technical contexts and how this impacts upon their own identity and mediates their relationships with others; if the elusive index is experienced, what is its impact?

In a large survey of young adults, it has recently been demonstrated that where a photograph is ascribed as real or fictional, keeping the photograph constant, viewers tend to have a stronger emotional reaction to photographs labelled as real, but think more about photographs labelled as fiction (Mendelson \& Papacharissi, 2008). 
Giving a photograph a real or fictional label offers a useful probe for exploring the indexical dimension with children in design contexts and could have much to tell us about the quality of the photograph as a cultural arbitrator. Indeed this research has significant implications in learning contexts for children's personal, social and emotional education as and when child-centric ways can be developed.

This dimension of the real and fictional to explore children's affective and cognitive responses to the photographic image is a new area of investigation in the eCUTE project. One way to advance this area of research is to use multimedia prototypes which embed the real and fictional in the user experience. To facilitate children's discourse around photographs of their cultural context, a social-constructivist approach will be taken. This research will be further extended by investigating whether or not being able to touch and manipulate digital images potentiates or changes the nature of these responses.

\section{THE PHOTOGRAPH AS A CULTURAL ARBITRATOR}

The final section of this paper will review the benefits and challenges of using the photograph as a cultural arbitrator with children and young people and how the changing nature of the index construct facilitates this dialogue between design stakeholders.

\subsection{Benefits}

\subsubsection{Stakeholder Role and Child's Agency}

The photograph as a cultural arbitrator assigns value to children and young people as design stakeholders by embracing their view, recognises that they are digital natives and that they assimilate and exploit technology in ways that the design team cannot fully appreciate, due to different technological experiences. It captures features of the child's world that contributes to immediate identity and meaning: who they are, why they are and what they are. It provides a detailed visual field for critical analysis and interpretation for visual content.

\subsubsection{Accessibility}

Is accessible for all children, does not require particular skill or craft, in this sense open to all and used by all; is democratic. It is a medium that has become native to children and young people, and that is increasingly used for communication, replacing text. The process is fun, active, associated with leisure time and easy, which makes buy in with children straightforward.

\subsubsection{Child's Cultural Perspective}

Recognises and extracts the visuality of the child's world, their consumption of media, their immersion in it and their role as a consumers. Images of children's own visual culture, what they look at and see, what they are attracted to, what fits with their visual world, what they see as relevant and worthy of their focus. Helps designers to understand users, to see their world and to judge what aspects of that world are worthy of representation recognising that any feature of a product or how it is derived must be in children's best interests.

\subsubsection{Indexical Transience}

Digital photographs are of the "now", they aren't laden with the indexical reverence of the analogue image, are transient, here today, gone tomorrow providing a more fluid, malleable medium to promote dialogue, discussion and knowledge transference. Productive, creative, positive, contributory, the digital medium can be transposed, transferred, modified, manipulated and is easily integrated into digital content for serious games.

\subsection{Challenges}

\subsubsection{Ethical safety}

It needs robust ethical controls and practices to ensure that children, young people, and their parents are protected. It requires professional approaches to interventions where photographs are used in communication with children to ensure that issues are dealt with in common sense ways and recognising children's particular sensitivities.

\subsubsection{Digital Storage Controls}

Needs robust digital storage controls to ensure that images are kept and stored in ways which make them accessible to the project and destroyed once they no longer have any purpose or usage potential.

\section{DISCUSSION}

\subsection{Changing value of the photograph}

The indexicality of the image, its relationship with the subject and the reverence afforded is being watered down by sheer volume. Images in the context of family and personal life will always carry meaning and emotional power, but the more public use of photographs in everyday life means that the majority of images may never be looked at more than once in a social network before they disappear into obscurity.

Digital images at the disposal of young people are treated with much less reverence, are manipulated, chopped, cropped and generally treated like play dough; the digital plasticine of everyday life with which to mould and sculpt their social interactions and exchanges. The vulnerabilities of changing digital technologies and storage mechanisms mean that much day to day visual experience is 
becoming transitory and short lived - visual chatter by visual chatterboxes which will never find its way into a treasured biscuit tin or family album for future posterity. The visual manifestations of experience have become the latest disposable item.

Naturally there is a continuum, at one end the photograph as a revered index of the real, but at the other the photograph as the ultimate throw away, life's experience captured in a moment to be consumed, then forgotten.

\subsection{Use of the photograph in design}

The changing agency of children and young people, their native abilities to engage with and exploit technologies within their own cultural context mean that much of their expertise and experience is unknown to adults - either in relationships with family and teachers and as users in a design context.

We as designers will never experience technology and visual culture in the same way that children have; we cannot put the clock back to experience their world. Children use photographs as mediators of communication, images are now transient, relevant today, passed over tomorrow - and the value of the majority of images is now negligible. How have the social skills of recent generations of children changed? How has the visual supported this changing agency? These are important questions that are only just being raised.

\subsection{Use of the photograph in design}

Methods to engage stakeholders should be of the day and change with the day; if trends continue, the visual world will continue to assert its stranglehold on culture and designers of educational technology who don't play to these trends will design products that are less likely to achieve their desired outcomes in the lives and education of children.

To create serious games for these users, imagining that a design team of experts can predict what they will enjoy is naïve, and will put at serious risk project outcomes. Not recognising the role of the visual record will be like the market researcher not attending to data. The primacy of numerical data may well be lessened - or may have to change but the role of the photographic image as a cultural arbitrator will undoubtedly evolve and methods must evolve in parallel.

\section{REFERENCES}

Bannister, E.N. and Booth, G.J. (2005) Exploring innovative methodologies for child-centric consumer research. Qualitative Market Research: An International Journal, 8(1), p. 157.
Barthes, R. (1993) Camera Lucida - Reflections on Photography, Vintage, London.

Barthes, R. (1977) Image, Music, Text, Hill and Wang, New York.

Batchen, G. (2004) Forget me Not: Photography and Remembrance. Van Gogh Museum, Amsterdam. Princeton Architectural Press, New York.

Bennett, M.J. (1993) Towards ethnorelativism: A developmental model of intercultural sensitivity. In M. Paige (ed.) Education for the intercultural experience. Intercultural Press. Yarmouth, Maine, ME.

Bolter, J.D and Grusin, R.A. (1996) Remediation. Configurations, 4(3), pp. 311-358.

Chamberlain, S., Sharp, H. and Maiden, N. (2006) Towards a Framework for Integrating Agile Development and User Centred Design. Proceedings of XP 2006, 1(1), pp. 143-153.

Christensen, P. and James, A. (2000) Research with Children: Perspectives and Practices. Falmer Press, London.

Di Bello, P. (2008) Seductions and Flirtations: Photographies, histories, theories. Photographies, 1(2), pp. 143-155.

Druin, A., Bederson, B., Boltman, A., Miura, A., Knotts-Callahan, D. and Platt, M. (1999) Children as our technology design partners. In A. Druin (ed) The Design of Children's Technology, pp. 51-72, Morgan Kaufmann, San Francisco.

Dzenko, C. (2009) Analog to Digital: The Indexical Function of Photographic Images. Afterimage: The Journal of Media Arts and Cultural Criticism, Media Literacy Special Issue, 37(2), pp. 19-23.

Guha, M.L, Druin, A., Chipman, G., Fails, J.A., Simms, S. and Farber, A. (2004) Mixing Ideas: A New Technique for Working with Young Children as Design Partners. Proceedings of Interaction Design and Children: Building a Community, pp. 35-42.

Hall, L., Jones, S., Hall, M., Richardson, J. and Hodgson, J. (2007) Inspiring design: the use of photo elicitation and lomography in gaining the child's perspective. Proceedings of British $\mathrm{HCl}$, pp. 23-33.

Higonnet, A. (1998) Pictures of Innocence: The History and Crisis of Ideal Childhood. Thames and Hudson, London.

Hill, R., Belanich, J., Lane, H., Core, M., Dixon, M., Forbell, E., Kim, J. And Hart, J. (2006) Pedagogically structured game based training: development of the ELECT BiLat simulation Conference Proceedings (Orlando, FL, November 2006).

Hofstede, G. (1991) Cultures and Organizations: Software of the Mind. McGraw-Hill, Maidenhead. 
Huizinga, J. (1950) Homo Ludens: A Study of the Play-Element in Culture, Roy Publishers, New York, NY, USA.

Jan D., Herrera, D., Martinovski, B., Novick, D. And Traum, D. (2007) A computational model of culturespecific conversational behaviour. In Pelachaud, C., Martin, J-C., André, E., Chollet, G., Karpouzis, K., Pelé, D. (eds) Intelligent Virtual Agents IVA '07, pp. 45-56, Springer, Berlin.

Lee, D.H. (2009) Mobile Snapshots and Private Public Boundaries. Knowledge Technology and Politics, 22(1), pp. 161-171.

Lewis, A. and Lindsay, G. (1999) Researching Children's Perspectives. Open University Press 2000, Milton Keynes.

Luttrell, W. (2006) Making Culture Visible: Children's Photography, Identity and Agency. Conference Papers - American Sociological Association, Montreal, pp. 1-15.

Mendelson, A.L. and Papacharissi, Z. (2008) Reality vs Fiction: How defined realness affective cognitive and emotional responses to photographs. Visual Communication Quarterly, 14(1), pp. 2-14

Mendelson, A.L. and Papacharissi, Z. (2010) Look at us: Collective Narcissism in College Student Facebook Photo Galleries. In Papacharissi, Z. (ed) The Networked Self: Identity, Community and Culture on Social Network Sites, Routledge, Oxford.

Mitchell, W.J.T. (2005) What do pictures want? The lives and loves of images. The University of Chicago Press, Chicago.

Moss, G. (2001) Seeing with the camera: analysing children's photographs of literacy in the home. Journal of Research in Reading, 24(3), pp. 279292

Palmer, D. (2010) Emotional archives: online photo sharing and the cultivation of the self. Photographies, 3(2), pp. 155-171.

Peirce, C. S. (1931-58) Collected papers of Charles Sanders Peirce. Hartshorne, C. and Weiss, P. (eds), Harvard University Press, Cambridge, Mass.
Postman, N. (1982) The Disappearance of Childhood. Vintage Books, New York.

Prensky, M. (2001) On the Horizon. MCB University Press, West Yorkshire.

Rasmussen, K. (2004) Places for Children, Children's Places. Childhood, 11(1), pp. 155-173.

Rubinstein, D. and Sluis, K. (2008) A Life More Photographic: Mapping the Networked Image. Photographies, 1(1), pp. 9-28.

Scifo, B. (2009) The Sociocultural Forms of Mobile Personal Photographs in a Cross-Media Ecology: Reflections Starting from the Young Italian Experience. Knowledge Technology and Politics, 22(1), pp. 185-194.

Shen, S-T, Woolley, M. Prior, S. (2006) Towards Culture Centred Design. Interacting with Computers, 18(4), pp. 820-852.

Simon, H.A. (1999) The Sciences of the Artificial: Third Edition. The MIT Press, Cambridge, Massachusetts.

Smith, L. (2003) Turning Point. Textual Practice, $17(1)$, pp. 1-6.

Sutton, D. (2007) Real Photography. In Sutton, D., Brind, S., McKenzie, R. (eds) The State of the Real: Aesthetics in the Digital Age, pp. 162-171, I.B.Taurus, London, New York.

Tinkler, P. (2008) A fragmented picture: reflections on the photographic practices of young people. Visual Studies, 23(3), pp. 255-266.

Zman, B. (2008) Introducing Contextual Laddering to Evaluate the Likeability of Games with Children. Cognition, Technology and Work, 10(2), pp. 107117.

\section{Acknowledgement}

This work is partly supported by the European Community (EC) and is currently funded by the eCUTE project (FP7-ICT-2009-5) with university partners Heriot-Watt, INESC-ID, Augsburg, Wageningen, Jacobs University Bremen, Sunderland, Seikei, and Kyoto. 